\title{
Design and Fabrication of an Automatic Trash Remover for Open Channel Waterway for Micro Hydropower Plant Application
}

\author{
A. M. Shiddiq Yunus ${ }^{\mathrm{a}, *}$, Musrady Mulyadi $^{\mathrm{b}}$, Apollo $^{\mathrm{c}}$ \\ ${ }^{\text {a} E n e r g y ~ C o n v e r s i o n ~ E n g i n e e r i n g, ~ S t a t e ~ P o l y t e c h n i c ~ o f ~ U j u n g ~ P a n d a n g, ~ I n d o n e s i a . ~ E m a i l: ~ s h i d d i q ~ @ ~ p o l i u p g . a c . i d ~}$ \\ ${ }^{b}$ Energy Conversion Engineering, State Polytechnic of Ujung Pandang, Indonesia. \\ ${ }^{c}$ Energy Conversion Engineering, State Polytechnic of Ujung Pandang, Indonesia.
}

\begin{abstract}
Mitigation of catastrophic impacts of exhausted pollutants from conventional based power plants can be performed by extensively using renewable energy-based power plants. One of the promising renewable energy-based power plants in already matured technology is hydropower. However, large scale hydropower should be located on an appropriate site and is not economically effective for isolated and remote small communities. Micro-hydropower plants (MHPPs) can applied to fulfill the power requirements of such communities due to its inexpensive capital and low maintenance cost. Normally, MHPPs projects are finalized by civil construction to powerhouse. A simple trash filter is usually located before the intake of the penstock. This simple trash filter usually causes a problem related to trash collection that blocks the water debit into the penstock intake. This low capacity might cause the reduction of turbine's rotation, which in turn downgrade the voltage and frequency. Low voltage and frequency might harm consumers. In this paper, a new control mechanism based on Arduino Mega is introduced for automatic trash removal.
\end{abstract}

Keywords: Automatic; MHPP; remover; filter; trash

\section{Introduction}

It is inevitable to construct more renewable energybased power plants to mitigate the negative impacts of conventional based power plants on the global environment [1]. Therefore, many developed countries recently increase the installation of wind and PV panels to support their main grids [2-5]. However, these two types of power plants have some limitation including high initial cost [6], high maintenance cost [7] and problems related intermittency of its main energy sources [8]. One of the old and matured renewable energy technologies that have been widely installed all around the world is hydropower plants (HPPs). This type of power plant could be scaled up to several MWs, free of air pollutants and has low maintenance cost [9]. Construction of a new hydropower plant (HPP) should be in consideration of some perspectives, including the economic point of view [10].

For isolated and remote small communities, long power transmission and distribution are not cost-effective and impractical by large scale power plants such as HPP. However, the equality principle of giving electricity service is a must. For example, Indonesia targets to achieve $100 \%$

\footnotetext{
*Corresponding author. Tel.: + +62-823-4752-1449

Jalan Perintis Kemerdekaan km. 10, Tamalanrea

Makassar, 90245
}

electrification ratio in 2020 [11]. Currently, the electrification ratio has reached about $91.16 \%$, meaning that some other $8.84 \%$ of people do not enjoy electricity yet [12]. To achieve the aforementioned target of electrification ratio, Indonesian government has promoted the large projects of micro hydropower plants (MHPPs) which is the most suitable for isolated and remote communities. Moreover, it has several advantages including cost-effectiveness based on its type mostly Runoff-Rivers, where no large dam and water storage system are required [13]. It also could reach about 50 years of live operation period [14]. The implemented projects of MHPPs in Indonesia itself have been reached about 134.21 MW in range projects of 2011-2015 [15].

An MHPP normally is constructed with a small budget due to its $\mathrm{kWs}$ scale $[16,17]$. Operation and maintenance are also managed in a very simple way. In Indonesian case for an instant, an MHPP operation and maintenance cost are collected from the community each month, therefore some technical designs as part of MHPP facilities are installed in the minimum standard. One of the common problems related to MHPP operation is blocked water to penstock intake by trash collection on the trash filter. The low debit of water could reduce the turbine rotation which in turn reduces the frequency and generated a voltage of the 
connected generator. This condition causing houses lights to be dimmed and become a clear indicator for the operator to visit the site and clean the trash. The problem might become even worst for the operator when the MHPP site, as usual, is located on the highland and quite far from the residence center. Moreover, the trash that commonly comes from leaves, branches and dry grasses that are flowing within the open channel waterway more potentially occur during the rainy session. The most horrible situation for the operator is if this condition occurs in the night time. In this paper, a design of automatic trash remover is proposed. The control mechanism is introduced to allow trashes to be removed automatically to prevent blocked water in the penstock intake.

\section{Research Methodology}

A trash filter in MHPP is normally placed on the penstock intake and used to filtrate trashes to avoid the trashes come along with the water into the penstock [18]. Traditionally, a trash filter is made simply like iron nets that capable of filtering the trashes and allowing the water to flow, the sample of a common trash filter is depicted in Fig. 1. To avoid trashes blocking the water into the penstock, the operator should regularly check the filter and cleaned it if necessary. As aforementioned above, sometimes a task to clean the filter becomes very challenging for the operator when it should be done in the night even in the worse rainy session. To anticipate it, an automatic scenario of trash rack is designed and proposed in this paper.

Work process of the automatic trash remover can be figured out in the flowchart diagram shown in Fig. 2.

The control system of the proposed system is set up in Microcontroller called Arduino Mega [19]. Some of the advantages of this type of controller are cheap, optimal power consumption and easy to implement [20].

There are only two controllers are employed in this mechanism: Flow and Limit Censor. A flow sensor has a duty to measure the flow capacity of water that pass the open channel before go through the intake of the penstock, when water flow lesser than $3.0 \mathrm{~m} / \mathrm{s}$ it is indicating that the trash has been blocked by some amount of trashes, therefore, in this point, trash rack should lift the trashes (in rotation mechanism) and in $90^{\circ}$ position, when other wing

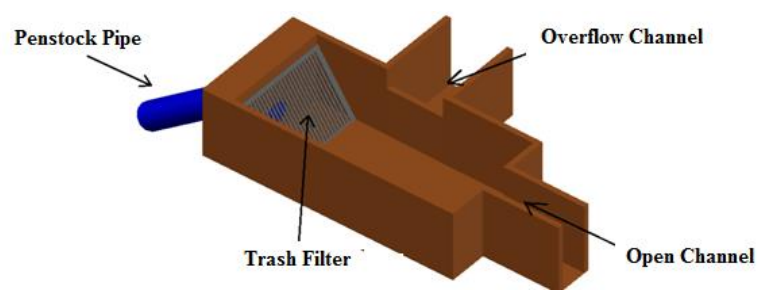

Figure 1. A typical type of MHPP trash filter trash rack press the limit switch, the rotation mechanism stop and trashes will be dropped on the conveyor which also run to transport the trashes into the bin. The design of the automatic trash remover can be seen in Fig. 3.

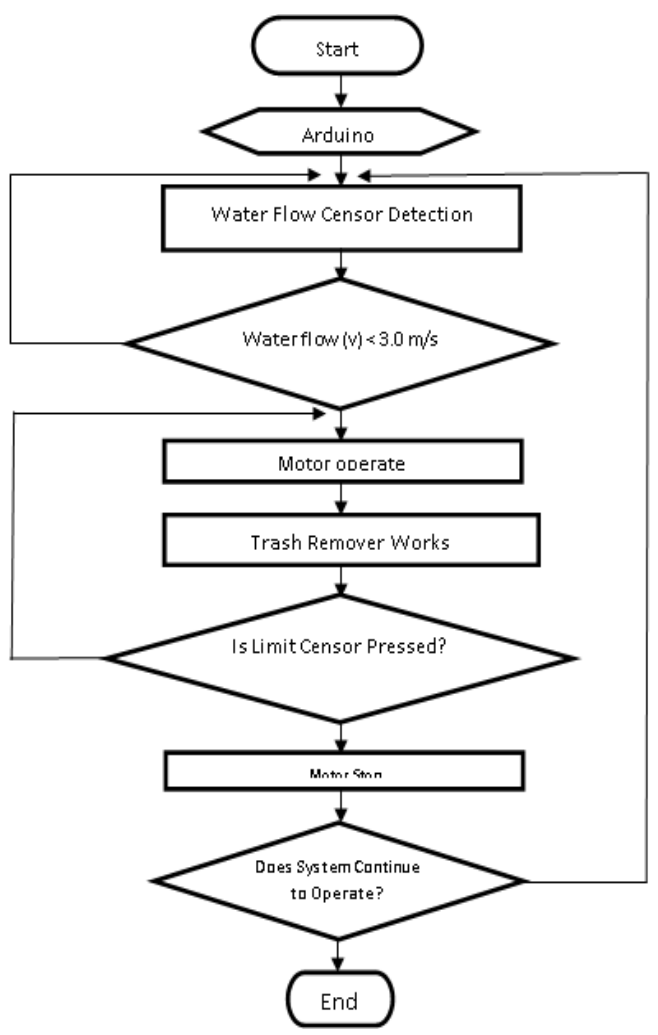

Figure 2. Flowchart of automatic trash remover for MHPP

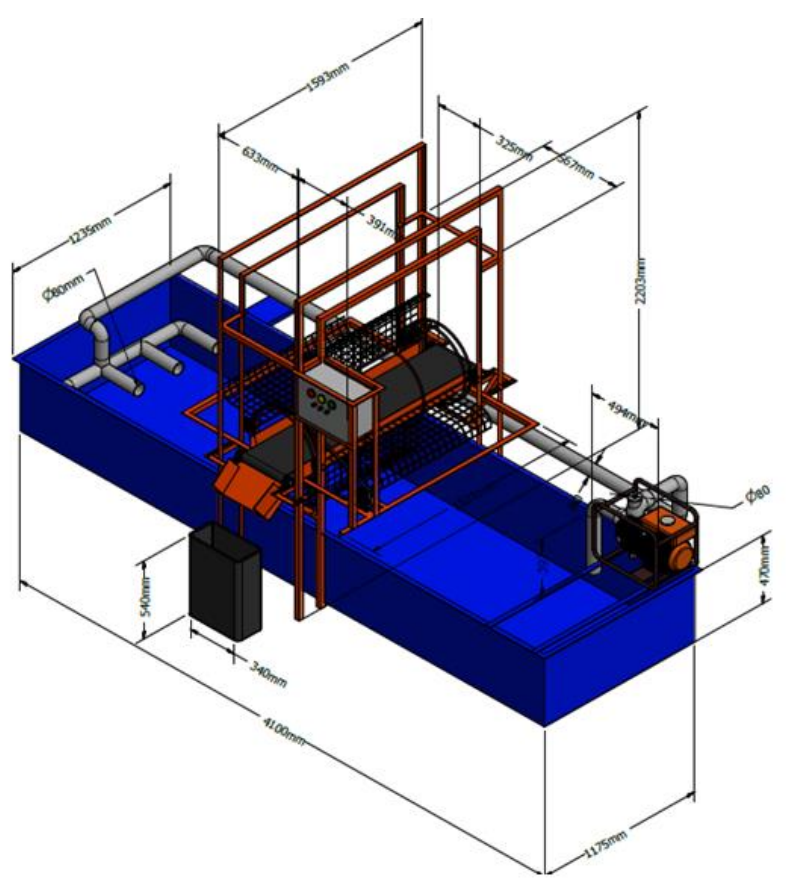

Figure 3. Lab scale of automatic trash remover for MHPP application 


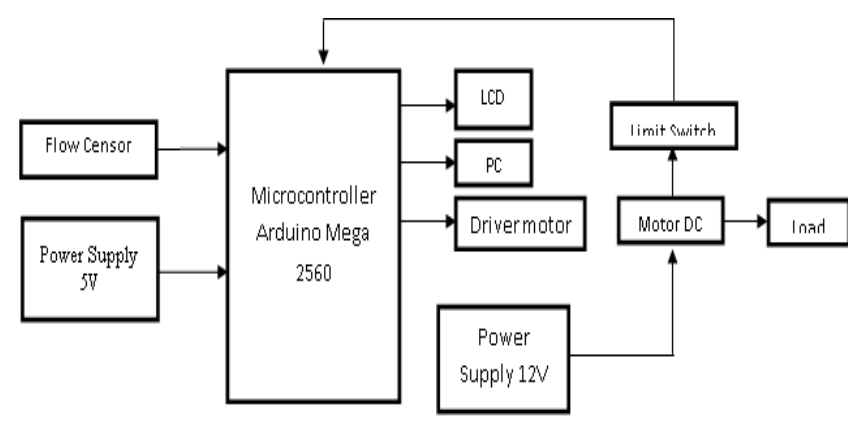

Figure 4. Block diagram of I/O of automatic trash remover microcontroller for MHPP application

The block diagram of the working steps of the device is shown in Fig. 4. Flow sensor and limit switch become the inputs of the Microcontroller to dictate whether the drive motor working to lift the trash or not. LCD is used to show the real-time data of the device such as Current, Voltage and Selector Position. All data can also be downloaded to the PC.

\section{Results and Discussion}

To test the performance of the device, two scenarios are applied; no-load test and with load test. The loads applied in the test are simulated with dried leaves which commonly fall into the open channel of MHPP and transport into the intake of the penstock. The mass variation of trash (shown in Fig. 5) is applied to see the performance of the device. Table 1 shows the performance of trash remover for some mass variation of the trash.

As noted in Table 1, when the laboratory test of the prototype was made, the automatic trash remover proved working properly to lift the trash using rotating trash filter shown in Fig. 1 for water flow less than $3 \mathrm{~m} / \mathrm{s}$. As observed in Table 1, the heavier the mass of trash becomes, the lesser the water velocity would be. Overall, the mechanical and control system of the device is working properly.

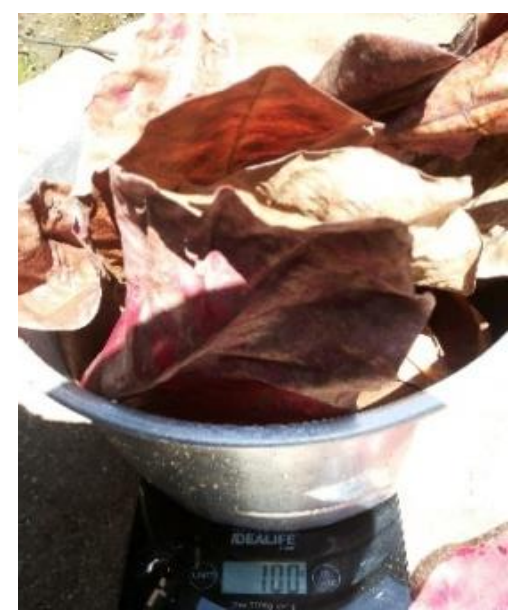

Figure 5. Common trash type (dried leaves) in open channel of MHPP
Table 1. Working performance of the automatic trash remover

\begin{tabular}{ccccc}
\hline & \multicolumn{2}{c}{$\begin{array}{c}\text { Average Water Velocity } \\
(\mathbf{m} / \mathbf{s})\end{array}$} & \multicolumn{2}{c}{$\begin{array}{c}\text { Status of Trash } \\
\text { Remover }\end{array}$} \\
$\begin{array}{c}\text { Mass of } \\
\text { Trash }\end{array}$ & $\begin{array}{c}\text { Before } \\
\text { Trash } \\
\text { Filter }\end{array}$ & $\begin{array}{c}\text { After } \\
\text { Trash } \\
\text { filter }\end{array}$ & $\begin{array}{c}\text { Trash } \\
\text { Filter }\end{array}$ & Conveyor \\
\cline { 2 - 5 } & 10 & 9.8 & Not Work & Not Work \\
55 & 9.44 & 3.56 & Not Work & Not Work \\
100 & 5.87 & 1.21 & Work & Work \\
155 & 5.18 & 1.11 & Work & Work \\
210 & 4.82 & 1.00 & Work & Work \\
\hline
\end{tabular}

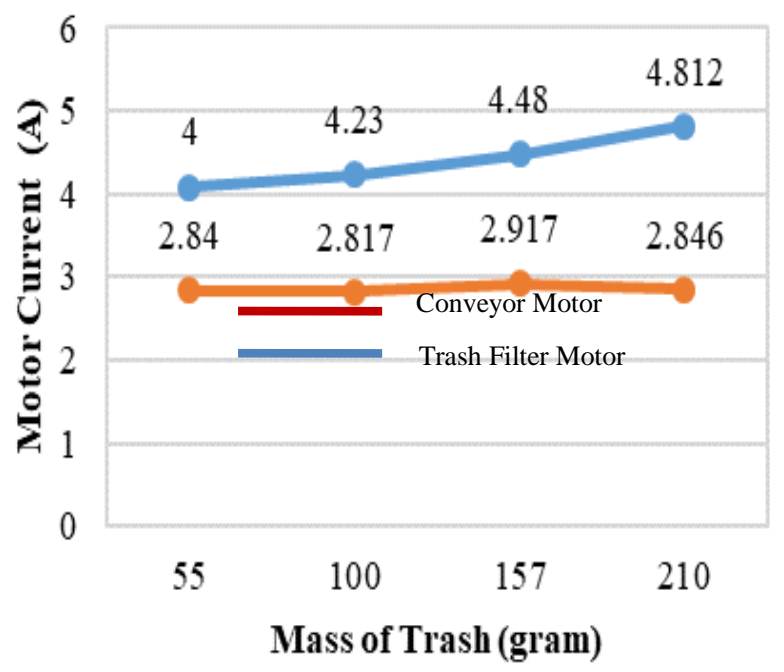

Figure 6. Current measurement for both trash filter motor and conveyor motor

To investigate the power consumption, current for both DC motors for Trash Filter and Conveyor is measured. As shown in Fig. 6, motor works harder when the load (trash mass) is larger, but still in the range of motor capability. Meanwhile, conveyor motor exhibits rather a stagnancy in consuming power.

\section{Conclusion}

In this paper, design, construction and experiment test of an automatic trash remover for MHPP application is introduced. It can be concluded that the system could work properly to remove the commonly dried leaves trash type automatically. The device eventually could avoid trashes in blocking the filter before intake of the penstock, thus, prevent the turbine from reduced speed. The benefits of this solution can be addressed as follows:

- Maintain the normal MHPP service

- Improve the MHPP operation lives.

- Reduce the working hours of MHPP operator 


\section{Acknowledgments}

Authors would like to appreciate the Research, Technology and Higher Education Ministry of Indonesia for funding support of the research through Applied Research Scheme with Contract Number: 155/SP2H/TL/DRPM/2019. The design and construction of this paper have been registered in the Intelectual Property Right of Indonesia with registered Number: S00201810819.

\section{References}

[1] Yah, N. F., Oumer, A. N. and Idris, M. S. 2017. Small scale hydropower as a source of renewable energy in Malaysia: A review. Renewable and Sustainable Energy Reviews, Vol. 72 (2017), pp. 228239. DOI: https://doi.org/10.1016/j.rser.2017.01.068

[2] Yunus, A.M.S., Abu-Siada, A., and Masoum, M.A.S. 2011. Effects of SMES on dynamic behaviors of type D-Wind Turbine Generator-Grid connected during short circuit. IEEE Power and Energy Society General Meeting. pp.1-6. DOI: 10.1109/PES.2011.6039276

[3] Shiddiq Yunus, A. M., Abu-Siada, A., and Masoum, M. A. S. 2011. Effect of SMES unit on the performance of type-4 wind turbine generator during voltage sag. IET Conference Publications. 2011(579 CP), pp. 94 DOI: $10.1049 / \mathrm{cp} .2011 .0137$

[4] Macias, E., and Ponce, A. 2006. Photovoltaic Solar Energy in Developing Countries. IEEE 4th World Conference on Photovoltaic Energy Conference, pp. 2323-2326 DOI: 10.1109/WCPEC.2006.279638

[5] Shiddiq Yunus, A. M., Abu-Siada, A., and Masoum, M. A. S. 2011. Improvement of LVRT capability of variable speed wind turbine generators using SMES unit. 2011 IEEE PES Innovative Smart Grid Technologies, ISGT Asia 2011 Conference, pp. 1-7 DOI: 10.1109/ISGT-Asia.2011.6167122

[6] https://www.windpowermonthly.com/article/1487102/firstindonesian-wind-farm-online (accessed, 06 February 2019)

[7] Ziegler, L., Gonzales, E., Rubert, t., Smolka, U., and Melero, J.J. 2018. Lifetime extension of onshore wind turbines: a review covering
Germany, Spain, Denmark, and the UK. Renewable and Sustainable Energy Reviews, Vol. 82, Part 1. pp. 1261-1271

DOI: https://doi.org/10.1016/j.rser.2017.09.100

[8] https://www.conserve-energy-

future.com/disadvantages_windenergy.php (accessed, 01 October 2018)

[9] Manzano-Agugliaro, F., et. al. 2017. An overview of research and energy evolution for small hydropower in Europe. Renewable and Sustainable Energy Reviews, Vol. 75, pp. 476-489. DOI: https://doi.org/10.1016/j.rser.2016.11.013

[10]Wongphat, M., and Premrudeepreechacharn, S. 2015. Evaluation of engineering and economic feasibility of micro-hydropower plan project. $5^{\text {th }}$ International Youth Conference on Energy (IYCE), pp. 1-6 DOI: 10.1109/IYCE.2015.7180813

[11] Achieving Universal Electricity Access in Indonesia. 2016. Asian Development Bank.

[12] Handbook of Energy and Economic Statistic of Indonesia. 2017. Ministry of Energy and Mineral Resources Republic of Indonesia.

[13]Palish, O. 2012. Small hydro power: technology and current status. Renewable and Sustainable Energy Reviews. Vol. 6 (2012), pp. 537. 556.

DOI: https://doi.org/10.1016/S1364-0321(02)00006-0

[14]Palish O. Micro-hydropower: status and prospects. 2002. Proc Inst Mech Eng, Part A: J Power Energy Vol. 216 (1):31-40. DOI: https://doi.org/10.1243/095765002760024827

[15] Anenomous, Statistic of New and Renewable Energy in Indonesia. 2016. Ministry of Energy and Mineral Resources of Indonesia

[16] www.esdm.go.id (accessed in August 2018)

[17]Erinofiardi, P., Gokhale, A., Date, A., Akbarzadeh, P., Bismantolo, A.F., Suryono, A.K., Mainil, A. and Nuramal. 2017. A review on micro hydropower in Indonesia, Energy Procedia 110 (2017), pp. 316-321 DOI: https://doi.org/10.1016/j.egypro.2017.03.146

[18] https://www.nrcan.gc.ca/sites/www.nrcan.gc.ca/files/canmetenergy/fil es/pubs/Intro_MicroHydro_ENG.pdf (accessed, 06 February 2019)

[19]https://www.arduino.cc/en/Guide/HomePage (accessed, 06 February 2019)

[20]Lomo, L., and Abraham. 2016. SMART Greenhouse using Microcontrollers Arduino Mega 2650 REV 3. Final Year Project. Yogyakarta. Electrical Engineering Department, Universitas Sanata Dharma. 